\title{
The Increasing of L-Type Methacrylate Acid Copolymer Level on Protection of Lactobacillus casei in the Microencapsulation Process using Spray Drying Method
}

\author{
Firnanda Yana Prastiwi, Sugiyartono*, Dwi Setyawan \\ Department of Pharmaceutics, Faculty of Pharmacy, Universitas Airlangga, Surabaya, East Java, Indonesia
}

Received: 22/07/2020

Accepted: 20/09/2020

Published: 20/12/2020

\begin{abstract}
Lactobacillus case $i$ is a type of probiotic that provides health benefits. Probiotics have an action target in the intestine but die at $\mathrm{pH}$ 2 in the stomach, so that need a delivery system that can protect probiotic bacteria in the stomach and released it in intestine. The matrix that is accordance probiotic delivery system is L-type methacrylic acid copolymer. The aim of this study is to determine the effect of $0.5 \%$ and $1.0 \%$ L-type methacrylic acid copolymer level on Lactobacillus casei protection in microencapsulation process by spray drying method at the inlet temperature of $110^{\circ} \mathrm{C}$. Lactobacillus casei probiotic microparticle was made into two formula that is $0,5 \%$ and $1,0 \%$ by spray drying method at the inlet temperature of $110^{\circ} \mathrm{C}$. Moisture content of microparticle in formula I was $9,56 \% \pm 0,21$ and in formula II was $7,34 \% \pm 0,17$. Mean of particle size of formula I and formula II were $3,34 \mu \mathrm{m} \pm 0,05$ and $4,08 \mu \mathrm{m} \pm 0,05$. P value of Lactobacillus casei protection test on the temperature of probiotic microparticle is 0.027 and the p-value of viscosity of matrix solvent is $0.011 .0 .5 \%$ and 1.0 L-type methacrylic acid copolymer level increased Lactobacillus casei protection against temperature during the microencapsulation process by spray drying method at inlet temperature of $110^{\circ} \mathrm{C}$.
\end{abstract}

Keywords: Probiotic, Spray drying, Copolymer, Lactobacillus casei

\section{Introduction}

Probiotic is microorganism which provides health benefits such as maintaining intestinal microflora balance, increasing defense against pathogenic invasion, treatment of diarrhea, allergic lactose, antihypertension, hypercholesterolemia and immunomodulators (1-3). The Most used probiotic is Lactobacillus casei which has many advantages such as resistant to antibiotics, effective against pathogenic bacteria, and more resistant to heat $(1,4,5)$. Probiotic died at $\mathrm{pH} 2$ in the stomach but has action target in the intestine with $\mathrm{pH} 6,15-7,88$ $(6-8)$. So that needs a delivery system which can protect probiotic in stomach and released it in the intestine. One of the forms of drug delivery systems is microparticles which are made by microencapsulation method. Microencapsulation aims to protect additives from unfavorable condition (9). Microparticle is expected to protect bacteria from the acidity of the stomach and released it in intestine immediately (10). A Matrix which accordance to the probiotic delivery system must have protection properties for additives in stomach and soluble in intestine, that is L-type methacrylic acid copolymer. L-type methacrylic acid copolymer is polymer compound from methacrylic acid and methyl methacrylate $(1: 1)$ which is soluble at $\mathrm{pH}$ above 6 and can form a layer which is resistant to stomach acid (11). One technique that can be used for microparticle making is spray drying. Spray drying advantages are low cost, producing sferis and small-sized microparticle form, and can be used on industrial scale. (12). One of the parameters of spray drying is inlet temperature. Determination

*Corresponding author: Sugiyartono, Department of Pharmaceutics, Faculty of Pharmacy, Universitas Airlangga, of inlet temperature is based on a minimum film-forming temperature (MFT) of the polymer. Using temperature above the MFT will produce a perfect film layer. L-type methacrylic acid copolymer has MFT above $85^{\circ} \mathrm{C}$ (13). Using inlet temperature of $98^{\circ} \mathrm{C}$ produces high moisture content (MC), that affects microparticle stability. Required moisture content range for probiotic microparticle is $2.80 \%-5.60 \%$ (14). Inlet temperature affects droplet drying rate and the output of microparticle moisture content (15). So this study chooses $110^{\circ} \mathrm{C}$ as a spray dryer inlet temperature that is expected to produce a good quality microparticle with more low moisture content value. This study aimed to determine the effect of $0.5 \%$ and 1.05 L-type methacrylic acid copolymer on Lactobacillus casei protection in microencapsulation process which is made by spray drying method at inlet temperature of $110^{\circ} \mathrm{C}$.

\section{Materials and Methods}

This was a laboratory experimental study. The material was Lactobacillus casei from Nutrition and Food Study Center of Gajahmada University, Yogyakarta, Indonesia. Other materials of this study were L-type methacrylic acid copolymer, de Man Rogosa Sharpe (MRS) broth media, Agar, sterile Phosphate Buffer Saline (PBS), Natrium Hydroxide $(\mathrm{NaOH})$, and sterile Aquadest.

\subsection{L-Type Methacrylic Acid Copolymer}

L-type methacrylic acid copolymer was examined with organoleptic method and FTIR Spectroscopy. Organoleptic

Campus C UNAIR J1. Dr. Ir. H. Soekarno, Surabaya 60115, East Java, Indonesia. Email: sgytnff@yahoo.com 
assess form, color, and smell compared with guidance. FTIR Spectroscopy was obtained through $\mathrm{KBr}$ pellet technique. $1 \mathrm{mg}$ substance with $100 \mathrm{mg} \mathrm{KBr}$ was crushed until homogenous, put in a vacuum dryer, and then formed with a hydraulic press until a thin translucent plate was obtained. The results showed specific wave numbers that state the analyzed existence of certain functional groups of compounds.

\subsection{Lactobacillus casei Starter Preparation}

5.22 gram MRS agar was solved into $100 \mathrm{ml}$ sterile aquadest. The solvent was heated and stirred with slow heating until it was boiled and homogenous then distributed into a test tube as much as $10 \mathrm{ml}$. Solvent was sterilized at $121^{\circ} \mathrm{C}$ for 15 minutes. A test tube of sterilized MRS agar solvent was tilted. An Ôse broodstock bacteria was swiped into MRS agar and incubated at $37^{\circ} \mathrm{C}$ for 48 hours to become ready for use starter of Lactobacillus casei. The starter can be stored at $4^{\circ} \mathrm{C}$ maximum for a month.

\subsection{Optimization of Lactobacillus casei Growth in MRS Broth Media}

\subsubsection{MRS broth media storage}

MRS broth was weighed as much as 5.22 gram and solved into $100 \mathrm{ml}$ aquadest. It was stirred until it was homogenous. Solvent was poured into Erlenmeyer and sterilized at $121^{\circ} \mathrm{C}$ for 5 minutes.

\subsubsection{Optimizing growth time of Lactobacillus casei}

Sterilized MRS broth media was added 1 Ose starter of Lactobacillus casei and incubated at $37^{\circ} \mathrm{C}$ using a thermoshaker. Samples were taken at 0, 4th, 6th, 8th, 12th, 16th, 18th, 24th, and 48th hour to be examined for $\mathrm{pH}$ and Lactobacillus casei viability test by Total Plate Count (TPC) of each time.

\subsubsection{Lactobacillus casei microparticle formulation}

Microparticle was made by $0.5 \%$ and $1.0 \%$ L-type methacrylic acid copolymer matrix. The composition of each formula can be seen in Table 1 .

\subsubsection{Lactobacillus casei suspension making}

MRS broth was weighed as much as 5.22 gram and solved into $100 \mathrm{ml}$ aquadest. It was stirred until it was homogenous and sterilized at $121^{\circ} \mathrm{C}$ for 5 minutes. Sterilized MRS broth media was added 1 Ose starter of Lactobacillus casei and incubated at $37^{\circ} \mathrm{C}$ using a thermoshaker according to the optimization of the growth time of probiotics. This solution was duplicated into two Erlenmeyers for two formulas. MRS broth was washed in probiotic cultures which had been incubated according to the optimization of growth time by centrifugation at a speed of $3000 \mathrm{rpm}$ for 10 minutes, then the solvent was removed and replaced with sterile aquadest for three times until no residual of MRS was seen. The precipitate was put into a fume hood until no liquid left. The dried sediment was weighed and sterile aquadest was added to $250 \mathrm{ml}$ in a calibrated sterile Erlenmeyer.

\subsubsection{L-type methacrylic acid copolymer matrix solvent making}

L-type methacrylic acid copolymer was weighed according to the amount listed for each formula (5 grams and 10 grams) and dissolved with $1 \mathrm{~N} \mathrm{NaOH}$ gradually until mucilage was formed. It was diluted with aquadest then stirred using a magnetic stirrer until $\mathrm{pH} 6$ was obtained so the matrix was soluble in water and homogeneous, then added sterile aquadest to $750 \mathrm{ml} .5$ grams of MRS broth was added to the matrix solution and stirred until it dissolved and homogeneous and then checked for $\mathrm{pH}$. The matrix compound was sterilized at $121^{\circ} \mathrm{C}$ for 15 minutes.

\subsubsection{Mixing Lactobacillus casei suspension with matrix solvent}

Lactobacillus casei suspension was added into matrix solvent until it reached $250 \mathrm{ml}$ while stirred using a magnetic stirrer. Then TPC of compound was checked.

\subsubsection{Lactobacillus casei microparticle making by spray drying method}

A probiotic compound and matrix suspensions were preadapted by heating to a temperature of $60^{\circ} \mathrm{C}$. Spray dryers were prepared with an inlet temperature of $110^{\circ} \mathrm{C}$ for microparticles making. Spray drying process was carried out until microparticles were formed then it was collected and weighed. Each microparticle formula was tested for Lactobacillus casei protection against the temperature of the microparticle.

\subsubsection{Microparticle Physical Characteristics Test}

Probiotic microparticle samples from each formula were tested to determine the moisture content (MC) and determine particle size. The sample also tested the temperature protection of Lactobacillus casei by calculating the Total Plate Count (TPC). Tests were conducted to see the effect of spray drying on the survival of Lactobacillus casei.

\subsection{Data Analysis}

Data of Lactobacillus casei protection against the temperature of microparticle was conducted by comparing the result of log TPC of Lactobacillus casei microparticle in each formula with $\log$ TPC probiotic before spray drying. The statistical test used independent $t$-test with a significant level of $95 \%(\alpha=0,05)$ to prove the ignificant differences between formulas.

Table 1: Design of liquid formula (feedstock) used in probiotic microparticles making

\begin{tabular}{lllll}
\hline & Materials & Function & Formula I & Formula II \\
\hline \multirow{2}{*}{ Probiotic Suspension } & Lactobacillus casei & Active ingredients & $10^{9} \mathrm{cfu} / \mathrm{ml}$ & $10^{9} \mathrm{cfu} / \mathrm{ml}$ \\
& Sterile Aquadest & Solvent & $250 \mathrm{ml}$ & $250 \mathrm{ml}$ \\
\hline \multirow{3}{*}{ Matrix Solvent } & L-type methacrylic acid copolymer & Matrix & 5 gram & 10 gram \\
& MRS broth & Nutrition & 5 gram & $5 \mathrm{gram}$ \\
& Sterile aquadest & Solvent & $750 \mathrm{ml}$ & $750 \mathrm{ml}$ \\
\hline
\end{tabular}

Description:

Formula I: Formula with $0.5 \%$ L-type methacrylic acid copolymer of $1000 \mathrm{ml}$

Formula II: Formula with 1.0\% L-type methacrylic acid copolymer of $1000 \mathrm{ml}$ 


\section{Results}

\subsection{Type L Methacrylate Acid Copolymers Characterization}

Type L methacrylic acid copolymers were characterized qualitatively including organoleptic and FTIR examinations. The results of the examination showed that the methacrylic acid copolymers used in this study met the requirements listed in the literature, indicating that the quality expected was appropriate.

\subsection{Optimization of Lactobacillus casei Growth in MRS Broth Media}

The results of the examination of $\mathrm{pH}$ and Log TPC of Lactobacillus casei at each incubation time are presented in table 2. From the results of $\mathrm{pH}$ suspension testing, it was found that there was a decrease in $\mathrm{pH}$ of the suspension caused by the production of lactic acid which occurred during the time of bacterial growth. From the results of Lactobacillus casei log TPC calculation, it can be seen that the log (exponential) phase is at the 6th to the 12th hour. The stationary phase occurs at the 12 th hour to the 18th hour. The optimum growth time is at the 12th hour which is the end of the exponential phase towards the beginning of the stationary phase with the highest log TPC value so that the incubation time of Lactobacillus casei for 12th hour is chosen as the growth time in the preparation of probiotic culture and then processed into microparticles.

\subsection{Measurement of Type L Methacrylate Acid Copolymers \\ Viscosity \\ The result of viscosity measurement showed that increasing} Type L Methacrylate Acid Copolymers level increased solvent viscosity. The result showed that matrix solvent viscosity of two formula was significantly different. This can be seen from the p-value of 0.011 which meets the requirements, $\mathrm{p}<0.05$. Lactobacillus casei protection against the temperature of microparticle test showed that formula II was bigger than formula I along with the increasing matrix. Statistical analysis showed that percentage of Lactobacillus casei protection against the temperature of microparticle of both formula had significant differences.

\subsection{Microparticle Physical Characteristics Test 3.4.1 Measurement of moisture content (MC) and particle size of Lactobacillus case $i$}

The result of measurement shows that moisture content of Lactobacillus casei in formula I and formula II are $9.56 \pm 0.21$ and $7.34 \pm 0.17$. Those results show that $0.5 \%$ and $1.0 \%$ type $\mathrm{L}$ Methacrylate Acid Copolymers decrease moisture content (MC) of the probiotic microparticle. Microparticle moisture content of each formula was exceeded of moisture content for probiotic microparticle, that is $2,80 \%-5,60 \%$. The result of measurement shows that particle size of Lactobacillus casei in formula I and formula II are $34 \mu \mathrm{m} \pm 0.05$ and $4.07 \mu \mathrm{m} \pm 0.05$. The particle size of Lactobacillus casei from formula I to formula II had been increased.

\subsubsection{Measurement of FTIR spectroscopy of Lactobacillus casei microparticle}

FTIR spectroscopy of Lactobacillus casei microparticle showed a shifting wave number in $\mathrm{OH}$ group compared with before microencapsulation process.

Table 2: Results of $\mathrm{Ph}$ and log TPC of Lactobacillus casei at each incubation time

\begin{tabular}{lllll}
\hline Time (hour) & Replication I & Replication II & Replication III & Mean \pm SD \\
\hline $\mathrm{pH}$ & & & & $5.65 \pm 0.01$ \\
\hline 0 & 5.66 & 5.66 & 5.65 & $5.55 \pm 0.00$ \\
4 & 5.55 & 5.55 & 5.55 & $5.73 \pm 0.01$ \\
6 & 5.73 & 5.74 & 5.73 & $5.05 \pm 0.00$ \\
8 & 5.05 & 5.05 & $5 . .05$ & $4.51 \pm 0.03$ \\
12 & 4.48 & 4.53 & 4.53 & $4.89 \pm 0.01$ \\
16 & 4.89 & 4.89 & 4.88 & $4.74 \pm 0.01$ \\
18 & 4.74 & 4.75 & 4.74 & $5.37 \pm 0.01$ \\
24 & 5.38 & 5.37 & 5.37 & $6.98 \pm 0.01$ \\
48 & 6.98 & 6.97 & 6.98 & $9.29 \pm 0.36$ \\
Log TPC & & & & $9.15 \pm 0.63$ \\
\hline 0 & 8.87 & 9.5 & 9.49 & $10.75 \pm 1.16$ \\
4 & 8.62 & 9.85 & 8.97 & $9.50 \pm 0.15$ \\
6 & 11.28 & 11.56 & 9.42 & $12.12 \pm 0.92$ \\
8 & 9.66 & 9.36 & 9.47 & $11.49 \pm 0.29$ \\
12 & 12.54 & 11.07 & 12.76 & $10.58 \pm 0.12$ \\
16 & 11.17 & 11.58 & 11.73 & $10.27 \pm 0.40$ \\
18 & 10.48 & 10.71 & 10.55 & $9.81 \pm 0.59$ \\
24 & 10.09 & 10.72 & 9.99 & \\
48 & 9.48 & 10.49 & 9.46 & \\
\hline
\end{tabular}

Table 3: Result of Type L Methacrylate Acid Copolymers Viscosity and Lactobacillus casei protection in against temperature of microparticle test

\begin{tabular}{llllll}
\hline Formulas & Replication I & Replication II & Replication III & Mean \pm SD & $p$-value \\
\hline Viskositas (Cp) & \multicolumn{5}{c}{} \\
\hline I & 2.99 & 2.74 & 3.09 & $2.94 \pm 0.18$ & 0.011 \\
II & 3.83 & 3.43 & 3.80 & $3.69 \pm 0.22$ & \\
\hline \multicolumn{7}{l}{ Lactobacillus casei } & protection in against temperature of microparticle test \\
I & $44,25 \%$ & $45,93 \%$ & $53,18 \%$ & $47,79 \% \pm 4,74$ & 0.027 \\
II & $65,53 \%$ & $63,64 \%$ & $55,70 \%$ & $61,62 \% \pm 5,22$ & \\
\hline
\end{tabular}


Table 4: The result of FTIR Spectroscopy Lactobacillus casei microparticle measurement

\begin{tabular}{llll}
\hline Group & $\begin{array}{l}\text { Measurement of Type } \mathbf{L} \\
\text { Methacrylate Acid Copolymers } \\
(\mathbf{c m}-1)\end{array}$ & $\begin{array}{l}\text { Measurement of particle size of } \\
\text { formula I } \\
(\mathbf{c m}-\mathbf{1})\end{array}$ & $\begin{array}{l}\text { Measurement of particle size } \\
\text { of formula II } \\
(\mathbf{c m}-1)\end{array}$ \\
\hline $\mathrm{C}=\mathrm{O}$ & 1724.17 & 1722.15 & - \\
$\mathrm{C}-\mathrm{O}$ & $1193.32 ; 1286.36$ & $1164.20 ; 1194.20 ;$ and 1278.24 & 1157,61 \\
Hydroxyl OH & 3511,$17 ; 2999,15 ;$ and 2952,15 & 3420,$12 ; 2993,21 ;$ and 2952,20 & 3395,$55 ; 2924,57$ and 2854,59 \\
& & & \\
Alkyl CH & 1389,$46 ; 1450,41 ;$ and 1485,42 & 1406,$25 ; 1449,24$ & 1384,$64 ; 1446,64$
\end{tabular}

The group $\mathrm{OH}$ of Type L Methacrylate Acid Copolymers before microencapsulation was in wave number of $3511,17 \mathrm{~cm}-$ 1 and after microencapsulation is $3420,12 \mathrm{~cm}-1$ (formula I) and $3395,55 \mathrm{~cm}-1$ (formula II). Hydrogen bonds cause the peak to widen and a shift toward shorter wave numbers can be ascertained so that it can be ensured that there is entrapment of bacteria by the L-type methacrylic acid copolymer matrix.

\section{Discussion}

The increase in type L methacrylic acid copolymer levels can increase the protection of Lactobacillus casei during the microencapsulation process with a spray dryer inlet temperature of $110^{\circ} \mathrm{C}$. Type $\mathrm{L}$ methacrylic acid copolymer is an anionic copolymer which is not water soluble. The $\mathrm{NaOH}$ compound causes the $\mathrm{L}$ type methacrylic acid copolymer to neutralize to form salts and the matrix can dissolve in water. The matrix will form a hydrogen bond which will cover the Lactobacillus casei so that it is protected from exposure to heat when spray drying (16). Increasing the level of matrix will minimize the decrease in the number of viable bacteria so that the percentage of protection will increase (17). Increased levels of L-type methacrylic acid copolymers increase viscosity so that the number of hydrogen bonds increases. The increasing amount of hydrogen bonds will form the structure of the microparticle walls that are increasingly rigid so that the ability to protect Lactobacillus casei will be even greater $(18,19)$. Hydrogen bonds can occur intermolecularly and intramolecularly and occur between $\mathrm{PO}^{-}$groups in the bacterial bilayer phospholipid layer with microparticle substance (18). Hydrogen bonding in large quantities causes the shrinkage process which is caused by trying to be reduced so that protection against bacteria will be even greater. The shift of wave numbers on $\mathrm{OH}$ groups shows the formation of hydrogen bonds in type $\mathrm{L}$ methacrylic acid copolymers so that Lactobacillus casei trapped inside the microparticle can be protected. Hydrogen bonding causes the peak to widen and a shift toward shorter wave numbers (18).

Increasing levels of type L methacrylic acid copolymers cause the matrix solution viscosity to increase (20). This causes the number of dissolved particles to increase so that the friction between particles increases and there is an increase in the viscosity of the solution. The increasing matrix level causes the particle size to increase so that the wall thickness of the microparticles increases and the ability of the microparticles to protect the bacteria inside will increase $(20,21)$. A decrease in inlet temperature will increase bacterial viability. The inlet temperature affects the drying speed of the droplets and the end result of moisture content of the microparticles. High inlet temperatures cause better heat transfer speeds so that evaporation of water occurs faster and moisture content will get smaller. In addition, a high flow rate can cause moisture content to decrease because the resulting particle size decreases and increases the droplet surface area so that the drying speed increases. Increasing the inlet temperature and flow rate will cause an increase in outlet temperature so that the moisture content will decrease (22).

The moisture content of microparticles influences bacterial viability after the spray drying process. A high flow rate will reduce the risk of cell damage due to heat from spray drying because of reduced heat transfer and an increasing number of viable bacteria, but this will increase the moisture content of the microparticles and will affect the surface morphology of microparticles (23). Pre-adaptation of feedstock solution which was warmed at $60^{\circ} \mathrm{C}$ before spray drying process aims to minimize the decreasing viability of Lactobacillus casei while spray drying process (20). In addition, the increased matrix level causes an increasing amount of solids in the feedstock, so that is limiting the spray dryer heat transfer which causes the number of viable bacteria to increase (17). Microparticles produced from formula I and formula II have particle sizes that increase along with increasing matrix levels. Particle size is an important parameter during reactivation of microorganisms in microcapsules, the small particle size will produce a large surface area that causes contact between microorganisms and nutrients for their growth to be greater (17). The results of the particle size of formula I and formula II were greater than the size of the Lactobacillus casei bacteria, which was 0.4-0.6 $\mu \mathrm{m}$ $\mathrm{x} 2-4 \mu \mathrm{m}$, so that is allowing bacteria to be well encapsulated in microparticles (24). The particle size is influenced by the viscosity of the liquid. Increasing matrix level will increase viscosity and cause an increased particle size (20). Low viscosity causes small-formed droplets with high solvent content that will evaporate while spray drying process and form the size of microparticles into small while the high viscosity of the solution will prevent shrinkage and produce larger particle sizes (25).

Lactobacillus casei protection against temperature of microparticle testing was carried out to determine the ability of type L methacrylic acid copolymers in protecting Lactobacillus casei during the spray drying process with inlet temperature of $110^{\circ} \mathrm{C}$. Type L methacrylic acid copolymers will form film layers because the temperature of spray drying is more than the minimum film-forming temperature (MFT) of the copolymer, which is $>85^{\circ} \mathrm{C}(13)$. The spray drying process causes a decreasing Lactobacillus casei $\log$ TPC values. The decreasing number of viable bacteria during the spray drying process can be caused due to the use of high temperatures (17). Heat and mechanical shear cause Lactobacillus casei bacteria cell damage. Cell damage is like denaturation of DNA and RNA, ribosomes damage, dehydration of cytoplasmic membranes, lipid peroxidation, and cell membranes that rupture and destroyed due to water displacement. Bacterial death can be 
caused by excessive droplet heat transfer, the integrity of cellular membranes can disappear due to increased membrane fluidity resulting in cell death (23). The decreasing log TPC of Lactobacillus case $i$ value indicates that there is an increasing percentage of Lactobacillus casei protection against the temperature of the two formulas.

\section{Conclusion}

Based the result of this study, it can be concluded that $0.5 \%$ and 1.0 L-type methacrylic acid copolymer level increased Lactobacillus casei protection against temperature during the microencapsulation process by spray drying method at inlet temperature of $110^{\circ} \mathrm{C}$.

\section{Ethical issue}

Authors are aware of, and comply with, best practice in publication ethics specifically with regard to authorship (avoidance of guest authorship), dual submission, manipulation of figures, competing interests and compliance with policies on research ethics. Authors adhere to publication requirements that submitted work is original and has not been published elsewhere in any language.

\section{Competing interests}

The authors declare that there is no conflict of interest that would prejudice the impartiality of this scientific work.

\section{Authors' contribution}

All authors of this study have a complete contribution for data collection, data analyses and manuscript writing.

\section{References}

1. Tripathi MK, Giri SK. Probiotic functional foods: Survival of probiotics during processing and storage. J Funct Foods [Internet]. 2014;9:225-41. Available from: http://dx.doi.org/10.1016/j.jff.2014.04.030

2. Fung WY, Lye HS, Lim TJ, Kuan CY, Liong MT. Roles of probiotic on gut health. InProbiotics 2011 (pp. 139-165). Springer, Berlin, Heidelberg.

3. Mandal V, Mandal NC. New health potentials of orally consumed probiotic microorganisms. InProbiotics 2011 (pp. 167-189). Springer, Berlin, Heidelberg.

4. Shao Y, Zhang W, Guo H, Pan L, Zhang H, Sun T. Comparative studies on antibiotic resistance in Lactobacillus casei and Lactobacillus plantarum. Food Control. 2015 Apr 1;50:250-8.

5. Mansouripour S, Esfandiari Z, Nateghi L. The effect of heat process on the survival and increased viability of probiotic by microencapsulation: A review. Ann Biol Res. 2013;4(4):83-7.

6. Hassanzadazar H, Ehsani A, Mardani K, Hesari J. Investigation of antibacterial, acid and bile tolerance properties of lactobacilli isolated from Koozeh cheese. InVeterinary Research Forum 2012 (Vol. 3, No. 3, p. 181). Faculty of Veterinary Medicine, Urmia University, Urmia, Iran.

7. Schell D, Beermann C. Fluidized bed microencapsulation of Lactobacillus reuteri with sweet whey and shellac for improved acid resistance and in-vitro gastro-intestinal survival. Food Research International. 2014 Aug 1;62:308-14

8. Solanki HK, Pawar DD, Shah DA, Prajapati VD, Jani GK, Mulla AM, Thakar PM. Development of microencapsulation delivery system for long-term preservation of probiotics as biotherapeutics agent. BioMed research international. 2013 Jan 1;2013.

9. Ansel HC, Allen L V. Ansel's Pharmaceutical Dosage Forms and Drug Delivery Systems. 10th Edition. Philadelphia: Lippincott Williams \& Wilkins; 2014. 300-304 p.

10. Chanana A, Kataria MK, Sharma M, Bilandi A, Bihani SGL, College SD, et al. MICROENCAPSULATION : ADVANCEMENTS IN APPLICATIONS. 2013;4(2):2-6.

11. Wang X, Zhang Q. European Journal of Pharmaceutics and Biopharmaceutics $\mathrm{pH}$-sensitive polymeric nanoparticles to improve oral bioavailability of peptide/protein drugs and poorly water-soluble drugs. Eur $\mathrm{J}$ Pharm Biopharm [Internet]. 2012;82(2):219-29. Available from: http://dx.doi.org/10.1016/j.ejpb.2012.07.014

12. Serna-cock L, Vallejo-castillo V. Probiotic encapsulation. 2016;(October 2013).

13. Thakral S, Thakral NK, Majumdar DK. Eudragit@: a technology evaluation. Expert opinion on drug delivery. 2013 Jan 1;10(1):131 49.

14. Kabeir BM. Viability of Bifidobacterium Pseudocatenulatum G4 after spray-Drying and Freeze-Drying. :37-43.

15. Mutukumira AN, Lee SJ. Beneficial Microorganisms in Food and Nutraceuticals. 2015

16. Bruce LD, McGinity W. Polymer interactions with drugs and excipient. In: Aqueous Polymeric Coatings for Pharmaceutical Dosage Forms 3rd Edition. 3rd Editio. New York: Informa Healthcare; 2008. 371 p.

17. Avila-reyes S V, Garcia-suarez FJ, Teresa M, Martín-gonzalez MFS, Bello-perez LA. Protection of L . rhamnosus by spray-drying using two prebiotics colloids to enhance the viability. Carbohydr Polym [Internet]. 2014;102:423-30. Available from http://dx.doi.org/10.1016/j.carbpol.2013.11.033

18. Lemon MT, Jones MS, Stansbury JW. Hydrogen bonding interactions in methacrylate monomers and polymers. 2007; (February)

19. Poddar D, Das S, Jones G, Palmer J, Geoffrey B, Haverkamp RG, et al. Stability of probiotic Lactobacillus paracasei during storage as affected by the drying method. Int Dairy J [Internet]. 2014 Available from: http://dx.doi.org/10.1016/j.idairyj.2014.04.007

20. Iravani S, Korbekandi H. Technology and potential applications of probiotic encapsulation in fermented milk products. 2015;52(August):4679-96.

21. Shi LE, Li ZH, Zheng W, Tang QX, Lu HM, Jiang JL, et al. Use of encapsulation technology for improving the viability of probiotics. In: Beneficial Microbes in Fermented and Functional Foods. New York: CRS Press; 2015. 241 p.

22. Fazaeli M, Emam-djomeh Z, Ashtari AK, Omid M. Food and Bioproducts Processing Effect of spray drying conditions and feed composition on the physical properties of black mulberry juice powder. Food Bioprod Process [Internet]. 2012;90(4):667-75. Available from: http://dx.doi.org/10.1016/j.fbp.2012.04.006

23. Taylor P, Behboudi-jobbehdar S, Soukoulis C, Yonekura L, Fisk I. Drying Technology: An International Journal Optimization of Spray-Drying Process Conditions for the Production of Maximally Viable Microencapsulated L . acidophilus NCIMB 701748 Optimization of Spray-Drying Process Conditions for the Production of Maximally Viable Microencapsulated 2013;(October):37-41.

24. Gad SE. Generally Recognized as Safe ( GRAS ). 2005;417-20.

25. Surini S. Study of Mucoadhesive Microspheres Based on Pregelatinized Cassava Starch Succinate as a New Carrier for Drug Delivery. 2009;(May 2014). 